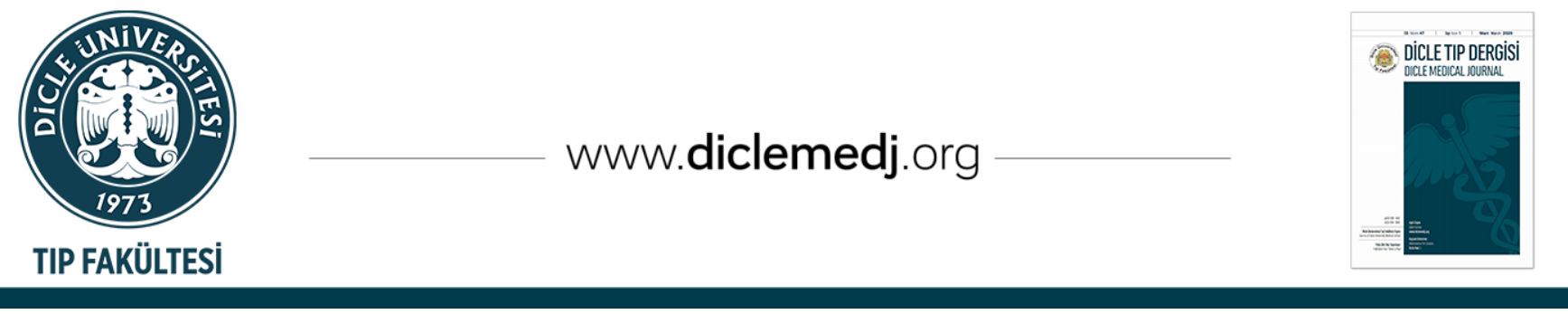

Özgün Araștırma / Original Article

\title{
Ampelopsin, Deneysel Böbrek İskemi Reperfüzyon Hasarında Oksidatif Stresi ve İnflamatuvar Sitokin Seviyelerini Azaltmaktadır
}

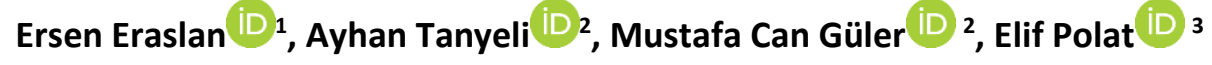 \\ 1 Fizyoloji Anabilim Dall, Tıp Fakültesi, Yozgat Bozok Üniversitesi, 66200, Yozgat, Türkiye \\ 2 Fizyoloji Anabilim Dal,, Tıp Fakültesi, Atatürk Üniversitesi, Erzurum, 25100, Türkiye \\ 3 Biyokimya Anabilim Dalı, Tıp Fakültesi, Atatürk Üniversitesi, Erzurum, 25100, Türkiye
}

Geliş: 26.11.2019; Revizyon: 22.05.2020; Kabul Tarihi: 29.05.2020

Öz

Amaç: Böbrek iskemi/reperfüzyon (İ/R) hasarı, böbrek disfonksiyonuna neden olan ve önlem alınmazsa ölüme kadar gidebilen sıkıntılı bir süreçtir. Bu çalışma, böbrek I/R hasarında farklı dozlarda kullanılan Ampelopsin'in (AMP) oksidatif stres ve proinflamatuvar sitokinler üzerine etkilerini araştırmayı amaçlamaktadır.

Yöntemler: 32 adet Wistar Albino erkek sıçan rastgele 4 gruba ayrıldı (n=8): Sham, İR, I/R+AMP 80mg/kg ve I/R+AMP $160 \mathrm{mg} / \mathrm{kg}$ grupları. I/R modelinde, renal pediküller 60 dakika süreyle klemplenerek iskemi oluşturuldu ve ardından klempler çıkarılarak 24 saat reperfüzyon uygulanarak I/R modeli tamamlandı. AMP uygulaması ise reperfüzyon başlatılmadan hemen önce gerçekleştirildi. AMP'nin oksidan ve antioksidan moleküller ile proinflamatuvar sitokinler üzerine etkileri değerlendirildi.

Bulgular: İ/R hasarı ile total antioksidan kapasite (TAK) ve süperoksit dismütaz (SOD) seviyeleri azalırken ( $<<0.001)$, malondialdehit (MDA), total oksidan kapasite (TOK) ve myeloperoksidaz (MPO) düzeyleri yükseldi $(p<0.001)$. AMP uygulanan gruplarda ise TAK ve SOD düzeyleri yükselirken ( $p<0.001)$, MDA, TAK ve MPO düzeyleri azaldı $(p<0.001)$. Ayrıca I/R hasarı ile artan proinflamatuvar sitokin seviyeleri AMP uygulanan gruplarda azaldı $(\mathrm{p}<0.001)$.

Sonuç: Bu veriler AMP’nin oksidatif stres kaynaklı böbrek hasarını azalttığını ve böbrek İ/R hasarı ile ilişsili inflamasyonu önlediğini gösterdi.

Anahtar kelimeler: Ampelopsin, Böbrek, İskemi/Reperfüzyon, Oksidatif Stres, İnflamasyon, Siçan

DOI: 10.5798/dicletip.755767

Correspondence / Yazıșma Adresi: Ersen Eraslan, Tıp Fakültesi, Fizyoloji Anabilim Dalı, Yozgat Bozok Üniversitesi, Yozgat, 66900, Türkiye, e-mail: ersen.eraslan@bozok.edu.tr 


\title{
Ampelopsin Reduces Oxidative Stress and Inflammatory Cytokine Levels in Experimental Kidney Ischemia Reperfusion Injury
}

\begin{abstract}
Objective: Renal ischemia/reperfusion (I/R) injury is a distressed process leading to renal dysfunction and may result in death if precautions are not taken. The aim of this study was to investigate the effects of different Ampelopsin (AMP) doses on oxidative stress and proinflammatory cytokines in renal I/R injury.

Methods: 32 Wistar Albino male rats were randomly divided into 4 groups (n=8): Sham, I/R, I/R+AMP 80 mg/kg and I/R+AMP 160 $\mathrm{mg} / \mathrm{kg}$ groups. In the I/R model, renal pedicles were clamped for 60 minutes to create ischemia, and then the clamps were removed and reperfused for 24 hours to complete the I/R model. AMP administration was performed just before reperfusion was initiated. The effects of AMP on oxidant, antioxidant molecules and proinflammatory cytokines were evaluated.

Results: The levels of total antioxidant status (TAS) and superoxide dismutase (SOD) decreased $(\mathrm{p}<0.001)$ while malondialdehyde (MDA), total oxidant status (TOS) and myeloperoxidase (MPO) levels increased due to I/R injury ( $\mathrm{p}<0.001$ ). In groups where AMP was administrated, TAS and SOD levels increased $(\mathrm{p}<0.001)$ while MDA, TAK and MPO levels performed a decrease $(\mathrm{p}<0.001)$. In addition, proinflammatory cytokine levels increased due to I/R injury and these parameters decreased in the groups treated with AMP $(\mathrm{p}<0.001)$.
\end{abstract}

Conclusion: These data showed that AMP reduces oxidative stress-induced renal injury and prevents renal I/R injury related inflammation.

Keyword: Ampelopsin, Kidney, Ischemia/Reperfusion, Oxidative Stress, Inflammation, Rat.

\section{GíRiş}

Akut böbrek hasarı $(\mathrm{ABH})$, patolojik olarak böbrek tübüllerinin ölümcül hasarı sonucu ortaya çlkan ani böbrek fonksiyon kaybının klinik bir sendromudur ${ }^{1}$. ABH'ye idrar çıkış hızında azalma, kreatin ve üre gibi metabolik atıkların birikmesi, hipoperfüzyon, tübüler hasar ve inflamasyon eşlik etmektedir ${ }^{2}$ ve ABH'nin temel nedenlerinden birisi böbrek iskemi reperfüzyon (I/R) hasarıdır ${ }^{3}$. $\dot{I} / R$ hasarı, kan dolaşımının geçici olarak kesilmesinden ve ardından kan akışının geri kazanılmasından kaynaklanır ve bu durum (reperfüzyon) hipoksik böbrek dokusunda yoğun bir oksijenlenme durumuna yol açar ${ }^{4}$. Hasar mekanizmaları arasında reaktif oksijen türlerinin (ROT) ve proinflamatuvar sitokinlerin üretimi ve çoklu enzimlerin aktivasyonu bulunmaktadır ${ }^{5}$. I/R hasarı gibi birçok olası etiyolojiye sahip hastalıklar ROT oluşumunu içerir ve antioksidan sistem hastalık sürecinde önemli rol oynar. Bu nedenle, ROT'un aracılık ettiği hastalıkların tedavisinde potansiyel ajanlar olarak antioksidan maddelerin kullanımı dünya çapında ilgi çekmiştiri. Geleneksel tıpta kullanılan çeşitli bitkilerin in vitro ve in vivo olarak antioksidan aktiviteye sahip olduğu gösterilmiştir. Bazı ilaçlar, doğal bileşikler ve antioksidan aktiviteye sahip bitkilerin ham özütleri, sıçan İ/R modellerinde nefroprotektif olup olmadıklarının belirlenmesi için değerlendirilmiștir6.

Dihidromyricetin olarak da bilinen Ampelopsin (AMP) [(2R,3R)-3,5,7-trihydroxy-2-(3,4,5trihydroxyphenyl)-2,3-dihydrochromen-4-one, AMP] bir flavanonol çeşididir. Ampelopsis grossedentata (vine tea), Güney Çin'de yaygın olarak bulunan tıbbi, yenilebilir bir bitkidir, fonksiyonel bir içecek olarak tüketilir ve bileşenleri birçok biyoaktif işlev göstermektedir 7,8 . Günümüze kadar yapılan araștırmalarda AMP'nin antikanser ${ }^{9}$, antioksidatif ${ }^{10}, \quad$ antiinflamatuvar ${ }^{11}$ ve antimikrobik $^{7}$ gibi birçok biyolojik aktiviteye sahip olduğu gösterilmiştir.

$\mathrm{Bu}$ çalışmada AMP'nin antioksidan ve antiinflamatuvar etkilerini böbrek İ/R ile oluşturulan $\mathrm{ABH}$ modelinde araştırmayı amaçladık. 


\section{YÖNTEMLER}

Bilateral böbrek İ/R modelini oluşturmak için 32 adet Wistar Albino erkek sıçan kullanıldı. Her grupta 8 adet sıçan olmak üzere dört grup oluşturuldu. Hayvanlar, suya ve yiyeceğe serbest şekilde erişimlerine izin verilerek $22 \pm 2$ OC ve 12 saat aydınlık-karanlık döngüsünde tutuldu. Araştırmalar, etik ve insani araştırma ilkelerine uygun olarak yapıldı ve Atatürk Üniversitesi Hayvan Deneyleri Yerel Etik Kurulu (30.06.2017/67) tarafindan onaylandı.

Deneyde kullanılan AMP (ChemFaces Biochemical, Wuhan, China) DMSO'da çözüldü ve intragastrik (ig.) olarak uygulandı. Çalışmada kullanılan AMP dozları Ye ve ark. yapmış olduğu serebral iskemi çalışması referans alınarak belirlendi12. Ketalar (Pfizer, İstanbul, Türkiye) ve ksilazin (Rompun Bayer, İstanbul, Turkey) intramusküler uygulandı.

Çalışma grupları; Grup I (sham grubu); anestezi altında retroperitoneal bölgeler $1.5-2 \mathrm{~cm}$ genişliğinde kesilerek açlıp kapatıldı. Grup II (İ/R grubu); ketamin $(75 \mathrm{mg} / \mathrm{kg})$ ve ksilazin (8 $\mathrm{mg} / \mathrm{kg}$ ) ile kombine anestezi altında retroperitoneal bölgeler $1.5-2 \mathrm{~cm}$ genişliğinde kesilip açıldı ve böbrek iskemisi, her iki böbrek pedikülünün üzerine vasküler kelepçeler (klemp) yerleștirilerek 60 dakika süreyle indüklendi. $\mathrm{Bu}$ işlemlerin ardından kelepçeler hassas şekilde çıkarılarak 24 saatlik reperfüzyon sürecine maruz birakıldı. Daha sonra retroperitoneal bölgedeki kesiler 3-0 ipek sütür kullanılarak kapatıldı. Grup III (I/R + AMP $80 \mathrm{mg} / \mathrm{kg}$ ) ve Grup IV (İ/R + AMP $160 \mathrm{mg} / \mathrm{kg}$ ) tedavi grupları olup, bu gruplara grup II'deki gibi cerrahi işlemler uygulandı ve reperfüzyondan hemen önce ilaç uygulaması yapıldı. Deneyin tamamlanmasindan (I/R süresi=25 saat) sonra anestezi altında sakrifiye edilen sıçanların böbrek dokuları hassas şekilde toplandl.

\section{Biyokimyasal ölçümler}

Doku örnekleri $100 \mathrm{mg}$ tartılarak $2 \mathrm{ml}$ fosfat tamponu içinde homojenize edilir. Homojenize edilmiş dokular, 5000 rpm'de 20 dakika boyunca $+4{ }^{\circ} \mathrm{C}$ 'de santrifüjlendi ve elde edilen süpernatanlar dikkatlice mikrosantrifüj tüplere $-80 \quad{ }^{\circ} \mathrm{C}$ 'de muhafaza edildi. Lipid peroksidasyonunun son ürünü olan malondialdehitin (MDA) ölçümü Ohkawa ve arkadaşlarının yöntemi kullanılarak yapıld ${ }^{13}$. Myeloperoksidaz (MPO) aktivitesinin ölçümü Bradley ve arkadaşlarının kullandıkları teknikle değerlendirildi ${ }^{14}$. Süperoksit dismutaz (SOD) enzim aktivitesi Sun ve ark. yöntemi kullanılarak belirlendi ${ }^{15}$. MDA, MPO ve SOD düzeyleri spektrofotometre kullanılarak ölçüldü. Total antioksidan kapasite (TAK=TAS (total antioxidant status)) ve total oksidan kapasite (TOK=TOS (total oxidant status)) ölçümü, piyasada bulunan kitler (Rel Assay Diagnostics, Turkey) ile tespit edildi. TOK/TAK oranı oksidatif stres indeksi (OSI) olarak kabul edildi. OSİ seviyesi şu şekilde ölçüldü: OSİ=[(TOK, $\mu \mathrm{mol} / \mathrm{L}) /(\mathrm{TAK}, \quad \mathrm{mmol} / \mathrm{L}) \times 10]^{16}$. Tümör nekrozis faktör-alfa (TNF- $\alpha$ ) ve interlökin-1beta (IL-1 $\beta$ ) (Elabscience Wuhan, China) gibi proinflamatuvar sitokinlerin seviyeleri ELISA kitler ile böbrek homojenatından ELISA okuyucu (ELISA, BioTEK powerwawe XS Winooski, U.K) kullanılarak değerlendirildi.

\section{İstatistiksel Analiz}

Veri analizi için SPSS 20 (SPSS Corporation, Chicago, IL, ABD) istatistik programı kullanıldı. Normal dağılıma uygunluk Shapiro Wilk testi ile incelendi. Nicel değişkenlerin gruplar arası karşılaştırılmalarında tek yönlü varyans analizi kullanıldı ve gruplar arasındaki farkı belirlemek için Tukey post hoc testi uygulandı. Veriler ortalama \pm standart sapma (SS) olarak verildi ve $\mathrm{p}<0.05$ değeri istatistiksel olarak önemli kabul edildi. 


\section{BULGULAR}

\section{Biyokimyasal Parametreler}

Böbrek İ/R hasarı üzerine farklı dozlarda AMP'nin oksidan ve antioksidan etkileri incelendi. Tablo 1'de TAK, TOK, OSİ, SOD, MDA ve MPO düzeyleri sunuldu. I/R grubunda TAK düzeyi sham grubuna klyasla azalırken $(\mathrm{p}<0.001)$, AMP uygulanan gruplarda arttı $(\mathrm{p}<0.001)$. TOK ve OSİ düzeyleri İ/R grubunda yüksek bulundu $(\mathrm{p}<0.001)$, ancak AMP uygulanan gruplarda bu değerler azaldı $(\mathrm{p}<0.001)$.

Tablo I: İskemi reperfüzyon ile oluşturulan böbrek hasarında farklı dozlarda ampelopsin uygulamasının biyokimyasal parametreler üzerine etkilerinin, gruplar arasında karşılaştırılması.

\begin{tabular}{|c|c|c|c|c|c|c|}
\hline $\begin{array}{l}\text { Deney } \\
\text { Grupla } \\
\text { rı } \\
(n=8)\end{array}$ & $\begin{array}{c}\text { TAK } \\
\text { (mmol/ } \\
\text { L) }\end{array}$ & $\begin{array}{c}\text { TOK } \\
(\mu \mathrm{mol} / \\
\mathrm{L})\end{array}$ & $\begin{array}{c}\text { OSI } \\
\text { (arbitrar } \\
\text { y unit) }\end{array}$ & $\begin{array}{l}\text { SOD } \\
\text { (U/mg } \\
\text { protei } \\
\text { n) }\end{array}$ & $\begin{array}{c}\text { MDA } \\
(\mu \mathrm{mol} / \\
\mathrm{g} \\
\text { protei } \\
\mathrm{n})\end{array}$ & $\begin{array}{c}\text { MPO } \\
\text { (U/g } \\
\text { protein } \\
\text { ) }\end{array}$ \\
\hline $\begin{array}{l}\text { Sham } \\
\text { (1) }\end{array}$ & $\begin{array}{c}2,30 \pm \\
0,50\end{array}$ & $\begin{array}{c}6,05 \pm \\
1,88\end{array}$ & $\begin{array}{c}0,31 \pm \\
0,26\end{array}$ & $\begin{array}{l}503,78 \\
\pm 19,09\end{array}$ & $\begin{array}{c}73,64 \pm \\
22,56\end{array}$ & $\begin{array}{c}43101,5 \\
4 \pm \\
1147,96\end{array}$ \\
\hline İ/R (2) & $\begin{array}{r}1,33 \pm \\
0,11^{\mathrm{a}}\end{array}$ & $\begin{array}{c}10,31 \pm \\
0,79^{a}\end{array}$ & $\begin{array}{c}0,78 \pm \\
0,11^{\mathrm{a}}\end{array}$ & $\begin{array}{l}261,33 \\
\pm 4,98^{\mathrm{a}}\end{array}$ & $\begin{array}{l}122,14 \\
\pm 4,64^{\mathrm{a}}\end{array}$ & $\begin{array}{c}88179,1 \\
5 \pm \\
8217,53 \\
\text { a }\end{array}$ \\
\hline $\begin{array}{l}\text { AMP } 80 \\
\mathrm{mg} / \mathrm{kg} \\
(3)\end{array}$ & $\begin{array}{c}1,97 \pm \\
0,15^{\mathrm{b}}\end{array}$ & $\begin{array}{r}6,88 \pm \\
0,62^{b}\end{array}$ & $\begin{array}{c}0,34 \pm \\
0,03^{\mathrm{b}}\end{array}$ & $\begin{array}{c}495,01 \\
\pm \\
30,23^{\mathrm{b}}\end{array}$ & $\begin{array}{c}75,80 \pm \\
3,50^{\mathrm{b}}\end{array}$ & $\begin{array}{c}47144,3 \\
3 \pm \\
980,93^{b}\end{array}$ \\
\hline $\begin{array}{l}\text { AMP } \\
160 \\
\mathrm{mg} / \mathrm{kg} \\
(4)\end{array}$ & $\begin{array}{c}2,39 \pm \\
0,24^{b}\end{array}$ & $\begin{array}{c}5,93 \pm \\
0,78^{\mathrm{b}}\end{array}$ & $\begin{array}{c}0,25 \pm \\
0,04^{\mathrm{b}}\end{array}$ & $\begin{array}{c}579,40 \\
\pm \\
38,61^{\mathrm{b}}\end{array}$ & $\begin{array}{c}67,16 \pm \\
3,77^{\mathrm{b}}\end{array}$ & $\begin{array}{c}40383,8 \\
7 \pm \\
4825,48 \\
\text { b }\end{array}$ \\
\hline
\end{tabular}

TAK; total antioksidan kapasite, TOS; total oksidan kapasite, OSI; oksidatif stress indeksi, SOD; süper oksit dismütaz, MDA; malondialdehit

MPO; myeloperoksidaz. Tüm veriler ortalama \pm SS olarak sunuldu $(n=8)$. $a p<0.001$ sham grubuna klyasla. $b p<0.001$ I/R grubuna klyasla.

Endojen antioksidan molekül olan SOD düzeyleri, sham grubuna kiyasla İ/R grubunda azald $1 \quad(\mathrm{p}<0.001)$, farklı dozlarda AMP uygulanan gruplarda ise SOD aktivitesi yükseldi $(\mathrm{p}<0.001)$.
Lipid peroksidasyonun bir göstergesi olan MDA ve nötrofil infiltrasyonunun bir belirteci olan MPO aktivitesi sham grubuna klyasla I/R grubunda yüksek bulundu $(\mathrm{p}<0.001)$. AMP uygulanan gruplarda MDA ve MPO düzeyleri azaldı $(\mathrm{p}<0.001)$.

Proinflamatuvar sitokinler olan TNF- $\alpha$ ve IL$1 \beta$ 'nın İ/R'u takiben AMP tedavisi ile nasıl değiştiği değerlendirdi (Şekil 1). Sham grubuna kıyasla I/R grubundaki TNF- $\alpha$ ve IL-1 $\beta$ seviyeleri yüksek bulundu $(\mathrm{p}<0.001) .80 \mathrm{mg} / \mathrm{kg}$ AMP ve $160 \mathrm{mg} / \mathrm{kg}$ AMP tedavi gruplarında TNF- $\alpha$ ve IL-1 $\beta$ düzeyleri I/R grubuna göre anlamlı derecede düşüktü $(\mathrm{p}<0.001)$.
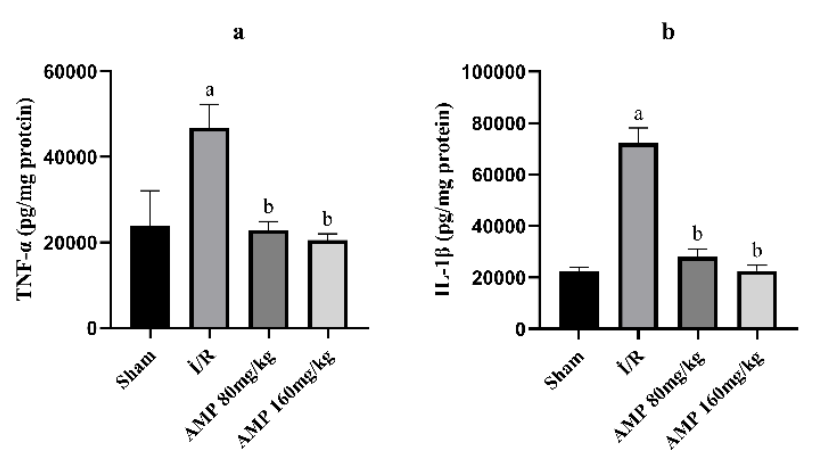

Şekil 1: İskemi reperfüzyon ile oluşturulan böbrek hasarında ampelopsin uygulamasının pro-inflamatuar sitokinler üzerine etkileri (a) TNF- $\alpha$ düzeyleri ve (b) IL$1 \beta$ düzeyleri. ap $<0.001$ sham grubuna klyasla, $b p<0.001$ İ/R grubuna kıyasla. Veriler ortalama \pm SS olarak sunuldu $(\mathrm{n}=8)$.

\section{TARTIŞMA}

$\mathrm{ABH}$, çeşitli nedenlerden kaynaklanan böbreğin disfonksiyonu olarak tanımlanır ve I/R hasarı ABH'nin en önemli nedenidir ${ }^{17}$. I/R'nin deney hayvanlarında ciddi histopatolojik ve biyokimyasal hasarlara yol açtığı bildirilmiştir ${ }^{18}$. Deneysel çalışmalarda AMP'nin meme kanseri ve otofaji ${ }^{7}$, oksidatif stres $^{10}$, inflamasyon ${ }^{11}$, beyin hasarl $^{19}$ ve kardiyovasküler hastalıklara ${ }^{20}$ karşı koruyucu etkileri rapor edilmiştir. Bu çalışmada ilk kez böbrek iskemi reperfüzyon hasarında, farklı dozlarda AMP uygulamasının bazı oksidan ve 
antioksidan moleküller ile proinflamatuvar sitokin düzeylerini nasıl etkilediği gösterildi.

Dokunun özellikle hipoksiden sonra yeniden oksijenlenmesi, oksidatif strese neden olan serbest radikallerin birikmesine neden olur ${ }^{21}$. Doku TOK seviyesi I/R grubunda anlamlı olarak arttığından oksidatif strese neden olmaktadır. Mevcut çalışmada iki farklı dozda uygulanan AMP, TOK seviyesini düşürüp TAK düzeyini arttırdı. Bu nedenle, AMP'nin sıçanlarda I/R kaynaklı oksidatif stres ve hasarı azaltmada etkili olduğu düşünüldü.

Böbrek İ/R hasarının sıralı olayları, hem iskeminin neden olduğu hücresel hasarı hem de renal hücre hasarına neden olan reperfüzyondan sonra damar endotel hücrelerinin aktifleşmesiyle sonuçlanan ROT üretimini kapsamaktadır ${ }^{22}$. Toksik olan ROT'u yok etmek için hücreler, SOD gibi antioksidan molekülleri de içeren birçok doğal antioksidan savunma sistemlerine sahiptir. I/R, ROT'un aşırı üretimine neden olur ki bu; endojen antioksidanların tükenmesine yol açabilir. $\mathrm{Bu}$ çalışmada, SOD aktivitesi sham grubu ile karşılaştırıldığında $\dot{\mathrm{I}} / \mathrm{R}$ grubunda anlamlı olarak daha düşüktü. Bu gözlemler, böbrek İ/R hasarının SOD aktivitesinde düşüş ile ilişkili olduğunu bildiren önceki çalışmalarla uyumludur'6. Sonuçlarımız farklı dozlarda AMP tedavisinin SOD aktivitesini arttırdığını gösterdi. AMP'nin SOD enzim aktivitesini arttırdığı rapor edilen birçok çalışma mevcuttur ${ }^{23,24}$ ve bu çalışmadaki bulguları desteklemektedir.

Doku MDA içeriği, lipid peroksidasyonunun en bilinen göstergelerinden biridir. $\dot{\mathrm{I}} / \mathrm{R}$ çalışmalarında sık araştırılan parametrelerden birisi MDA seviyesidir25. Bu çalışmada, İ/R'nin böbrek dokularında MDA içeriğini artırarak böbrek disfonksiyonuna neden olduğu gösterildi. Bu veriler, böbrek I/R hasarı sonrası artan MDA seviyeleri ile uyumludur ${ }^{26}$. Sonuçlarımız AMP uygulamasının MDA düzeyini anlamlı olarak azalttığını gösterdi. $\mathrm{Bu}$ bulgular, daha az oksidatif stres düzeyi sonucu daha az lipid peroksidasyonuna işaret etmektedir. Sonuçlarımızla tutarlı olarak AMP'nin çeşitli in vitro çalışmalarda MDA düzeyini baskıladığı gösterildi27. Mevcut çalışma, AMP uygulamasının lipid peroksidasyonu ve MDA üretiminde önemli bir azalmaya (hücresel hasarda azalmayı gösterir) yol açtığını göstermiştir. Böbrek İ/R hasarı, aşırı oksidatif strese yol açar. ROT’un aşırı üretimini azaltmak, böbrek hasarından sonra ikincil yıkımı en aza indirir ${ }^{28}$.

Polimorfonükleer nötrofil infiltrasyonu; doku İ/R, ilaç toksisitesi, şok ve benzeri nedenlerle ortaya çıkan akut hasarın özelliğidir ${ }^{18,29}$. Böbrek iskemisi ile nötrofillerin göçü ve aktivasyonu sonucu ROT, MPO, inflamatuvar faktörler ve benzerleri serbest kalarak böbrek hasarını arttırıp daha da şiddetlendirirler ${ }^{29}$. Bu çalışmanın sonuçları, AMP tedavisinin doku nötrofil infiltrasyonunu ve MPO aktivitesini önemli ölçüde önleyebildiğini ve dokuyu İ/R hasarına karşı koruyabileceğini göstermiştir. Wang ve arkadaşları AMP'nin, nötrofillerin infiltrasyonunu ve sepsis ile indüklenen akut akciğer hasarı olan farelerde MPO aktivitesinin aktivasyonunu baskıladığını bulmuştur ${ }^{30}$. ROT üretiminin AMP tarafından inhibe edilmesi, nötrofil aktivasyonu ile ROT üretimi arasındaki yakın iliş̧i nedeniyle nötrofil infiltrasyonunu azaltmaya katkıda bulunabilir.

ABH'de inflamatuvar yanıtın her zaman kritik bir faktör olduğu bilinmektedir. Böbrek I/R ile oluşturulan inflamatuvar süreç lökosit infiltrasyonunun artması, inflamatuvar mediatör üretimi ve endotel/lökosit etkileşiminin artması ile karakterizedir. $\mathrm{Bu}$ sırada birçok lökosit aktive edilir ve sonuçta daha fazla böbrek hasarı ile sonuçlanan hücresel apoptoz ve nekrozu indükleyebilen sitokinler, ROT ve enzimler serbest birakılır. Proinflamatuvar sitokinlerin ve kemokinlerin salınımı, lökositlerin hasarlı dokulara sızmasını teşvik edebilir ve inflamatuvar kaskadı 
alevlendirebilir ${ }^{31}$ Proinflamatuvar sitokinlerden IL-1 $\beta$ ve TNF- $\alpha$, böbrek hasarının ciddiyetini gösteren belirteçlerdendir. Daha önceki çalışmalarımıza paralel şekilde bu çalışmada da böbrek İR sonrasında proinflamatuar sitokin seviyelerinin arttı̆̆ bulundu18,32. Farklı dozlarda uygulanan AMP, İR hasarı ile artan sitokin seviyelerini azalttı. AMP ve sinonimi olan dihydromyricetin uygulanan birçok in vivo ve in vitro çalışmada proinflamatuvar sitokin seviyelerinin azaltıldığı rapor edilmiştir ${ }^{11,19,23}$. AMP'nin proinflamatuvar sitokinlerin üretimini baskılayarak böbrek hasarının azaltılmasına katkıda bulunabileceği gösterildi.

\section{SONUÇ}

Sonuç olarak, böbrek İ/R ile oluşturulan hasarda AMP tedavisinin oksidatif stresi azalttığı ve proinflamatuvar sitokinleri baskıladığı gösterildi. Ancak çalışmada yer alan parametrelerin serum seviyelerinin ölçülmemesi ve histopatolojik analizlerin gerçekleştirilmemesi çalışmadaki eksikliklerin birkaçıdır.

Etik Kurul Kararı: Araştırmalar, etik ve insani araştırma ilkelerine uygun olarak yapıldı ve Atatürk Üniversitesi Hayvan Deneyleri Yerel Etik Kurulu (30.06.2017/67) tarafindan onaylandl.

Çıkar Çatışması Beyanı: Yazarlar çıkar çatışması olmadığını bildirmişlerdir.

Finansal Destek: Bu çalışma her hangi bir fon tarafından desteklenmemiştir.

Declaration of Conflicting Interests: The authors declare that they have no conflict of interest.

Financial Disclosure: No financial support was received.

\section{KAYNAKLAR}

1. Doyle JF, Forni LG. Acute kidney injury: shortterm and long-term effects. Crit Care. 2016; 20: 188.

2. Bellomo R, Kellum JA, Ronco C. Acute kidney injury. Lancet. 2012; 380: 756-66.

3. Manoeuvrier G, Bach-Ngohou K, Batard E, et al. Diagnostic performance of serum blood urea nitrogen to creatinine ratio for distinguishing prerenal from intrinsic acute kidney injury in the emergency department. BMC Nephrol. 2017; 18: 173.

4. Basile DP, Anderson MD, Sutton TA. Pathophysiology of acute kidney injury. Compr Physiol. 2012; 2: 1303-53.

5. Montagna G, Hofer CG, Torres AM. Impairment of cellular redox status and membrane protein activities in kidneys from rats with ischemic acute renal failure. Biochim Biophys Acta. 1998; 1407: 99-108.

6. Perez-Meseguer J, Torres-Gonzalez L, Gutierrez-Gonzalez JA, et al. Anti-inflammatory and nephroprotective activity of Juglans mollis against renal ischemia-reperfusion damage in a Wistar rat model. BMC Complement Altern Med. 2019; 19: 186.

7. Zhou Y, Liang X, Chang H, et al. Ampelopsininduced autophagy protects breast cancer cells from apoptosis through Akt-mTOR pathway via endoplasmic reticulum stress. Cancer Sci. 2014; 105: 1279-87.

8. Wang Y, Ying L, Sun D, et al. Supercritical carbon dioxide extraction of bioactive compounds from Ampelopsis grossedentata stems: process optimization and antioxidant activity. Int J Mol Sci. 2011; 12: 6856-70.

9. Chang H, Peng X, Bai Q, et al. Ampelopsin suppresses breast carcinogenesis by inhibiting the mTOR signalling pathway. Carcinogenesis. 2014; 35: 1847-54. 
10. Hou X, Zhang J, Ahmad H, et al. Evaluation of antioxidant activities of ampelopsin and its protective effect in lipopolysaccharide-induced oxidative stress piglets. PLoS One. 2014; 9: e108314.

11. Qi S, Xin Y, Guo Y, et al. Ampelopsin reduces endotoxic inflammation via repressing ROSmediated activation of PI3K/Akt/NF-kappaB signaling pathways. Int Immunopharmacol. 2012; 12: 278-87.

12. Ye XL, Lu LQ, Li W, et al. Oral administration of ampelopsin protects against acute brain injury in rats following focal cerebral ischemia. Exp Ther Med. 2017; 13: 1725-34.

13. Ohkawa H, Ohishi N, Yagi K. Assay for Lipid Peroxides in Animal-Tissues by Thiobarbituric Acid Reaction. Anal Biochem. 1979; 95: 351-8.

14. Bradley PP, Priebat DA, Christensen RD, et al. Measurement of cutaneous inflammation: estimation of neutrophil content with an enzyme marker. J Invest Dermatol. 1982; 78: 206-9.

15. Sun Y, Oberley LW, Li Y. A Simple Method for Clinical Assay of Superoxide-Dismutase. Clin Chem. 1988; 34: 497-500.

16. Harma $M$, Harma $M$, Kocyigit $A$, et al. Increased DNA damage in patients with complete hydatidiform mole. Mutat Res-Gen Tox En. 2005; 583: 49-54.

17. Friedewald JJ, Rabb H. Inflammatory cells in ischemic acute renal failure. Kidney Int. 2004; 66: 486-91.

18. .Eraslan E, Tanyeli A, Polat E, et al. 8-BrcADPR, a TRPM2 ion channel antagonist, inhibits renal ischemia-reperfusion injury. J Cell Physiol. 2019; 234: 4572-81.

19. Ye XL, Lu LQ, Li W, et al. Oral administration of ampelopsin protects against acute brain injury in rats following focal cerebral ischemia. Exp Ther Med. 2017; 13: 1725-34.
20. Qiu ZP, Zhou JX, Hu JJ, et al. Total flavonoids from Ampelopsis megalophylla suppress proliferation of vascular smooth muscle cells in vivo and in vitro. Braz J Pharm Sci. 2017; 53.

21. Levigne D, Tobalem M, Modarressi A, et al. Hyperglycemia Increases Susceptibility to Ischemic Necrosis. Biomed Research International. 2013.

22. Yoshitomi T, Hirayama A, Nagasaki Y. The ROS scavenging and renal protective effects of pH-responsive nitroxide radical-containing nanoparticles. Biomaterials. 2011; 32: 8021-8.

23. Hou X, Wang T, Ahmad H, et al. Ameliorative effect of ampelopsin on LPS-induced acute phase response in piglets. J Funct Foods. 2017; 35: 489-98.

24. Kou X, Li J, Liu X, et al. Ampelopsin attenuates the atrophy of skeletal muscle from d-gal-induced aging rats through activating AMPK/SIRT1/PGC-1alpha signaling cascade. Biomed Pharmacother. 2017; 90: 311-20.

25. Derya Güzel AT. p-Kumarik Asit, Renal İskemi Reperfüzyon Kaynaklı Akut Pulmoner Hasarı Azaltır. Sakarya Tıp Dergisi. 2018; 8: 644-9.

26. Bircan B, Cakir M, Kirbag S, et al. Effect of apelin hormone on renal ischemia/reperfusion induced oxidative damage in rats. Ren Fail. 2016; 38: 1122-8.

27. Song Q, Liu L, Yu J, et al. Dihydromyricetin attenuated Ang II induced cardiac fibroblasts proliferation related to inhibitory of oxidative stress. Eur J Pharmacol. 2017; 807: 159-67.

28. Lerman L, Textor SC. Pathophysiology of ischemic nephropathy. Urol Clin N Am. 2001; 28: 793-+.

29. Linas SL, Shanley PF, Whittenburg D, et al. Neutrophils accentuate ischemia-reperfusion injury in isolated perfused rat kidneys. Am J Physiol. 1988; 255(4 Pt 2): F728-35. 
30. Wang YC, Liu QX, Zheng Q, et al. Dihydromyricetin Alleviates Sepsis-Induced Acute Lung Injury through Inhibiting NLRP3 Inflammasome-Dependent Pyroptosis in Mice Model. Inflammation. 2019; 42: 1301-10.

31. Rabb H, Griffin MD, McKay DB, et al. Inflammation in AKI: Current Understanding, Key Questions, and Knowledge Gaps. Journal of the American Society of Nephrology. 2016; 27 : 371-9.
32. Eraslan E, Tanyeli A, Polat E, et al. Evodiamine alleviates kidney ischemia reperfusion injury in rats: A biochemical and histopathological study. J Cell Biochem. 2019; 120: 17159-66. 